\title{
Principles and Practice of Nonpharmacological Interventions to Reduce Cardiometabolic Risk
}

\author{
Samuel Dagogo-Jack Nonso Egbuonu Chimaroke Edeoga \\ Division of Endocrinology, Diabetes and Metabolism, University of Tennessee Health Science Center, \\ Memphis, Tenn., USA
}

\section{Key Words}

Prediabetes $\cdot$ Diet $\cdot$ Exercise $\cdot$ Smoking cessation $\cdot$

Community prevention

\begin{abstract}
The components of the metabolic syndrome, including prediabetes, prehypertension and dyslipidemia, represent prodromal stages of major cardiometabolic disorders. Lifestyle interventions have been shown to ameliorate or prevent the progression of individual components of the metabolic syndrome. The specific interventions utilized in randomized controlled studies often include dietary modification and physical activity. The effects of smoking cessation and the reduction of psychosocial stress on cardiometabolic risk factors need to be studied more. Because of the close concordance between the metabolic syndrome and multiple cardiometabolic diseases, the adoption of an effective lifestyle change upon initial recognition of the metabolic syndrome can be expected to delay or prevent the future development of sequelae such as diabetes, hypertension, and atherosclerotic cardiovascular and cerebrovascular diseases. Such a nonpharmacological approach to primary prevention and disease interruption carries enormous public health significance. Meeting the challenge of an implementation of effective lifestyle change at the community level requires (a) a
\end{abstract}

system for the identification of at-risk populations, (b) an optimization of the knowledge base and practices of health care providers, and (c) a piloting of targeted biobehavioral intervention programs. Once identified, persons and communities at risk for cardiometabolic disorders can be empowered through increased health and nutritional literacy, the promotion of lifestyle interventions, provision of community resources, and pertinent legislative action that rewards preventive behavior. This paper reviews landmark studies that demonstrate the principles of nonpharmacological approaches to the reduction of cardiometabolic risk. We also discuss the physiological and emerging molecular genetic mechanisms that underlie the efficacy of lifestyle interventions.

Copyright $\odot 2010$ S. Karger AG, Basel

\section{Prediabetic States and the Metabolic Syndrome}

The term 'prediabetes' refers to impaired glucose tolerance (IGT) and impaired fasting glucose (IFG), two intermediate metabolic states between normal glucose tolerance and diabetes. IGT is defined by a plasma glucose level of $140-199 \mathrm{mg} / \mathrm{dl}, 2 \mathrm{~h}$ following the ingestion of a 75 -gram oral glucose solution. IFG is defined by a fasting plasma glucose of $100-125 \mathrm{mg} / \mathrm{dl}$ [1]. IFG and IGT are risk

\section{KARGER}

(c) 2010 S. Karger AG, Basel

Fax +41613061234

E-Mail karger@karger.ch

www.karger.com
Accessible online at: www.karger.com/mpp
Samuel Dagogo-Jack, MD

University of Tennessee Health Science Center

920 Madison Avenue (Suite 300A)

Memphis, TN 38163 (USA)

Tel. +1 901448 5318, Fax +1 901448 5332,E-Mail sdj@utmem.edu 
Fig. 1. Sequelae of the metabolic syndrome. Individual components of the syndrome are recognized risk factors for type 2 diabetes and/or macrovascular disease. Progression to diabetes initiates susceptibility to microvascular complications and further accentuates the risk for macrovascular disease. $\mathrm{BP}=$ Blood pressure; $\mathrm{FPG}=$ fasting plasma glucose.

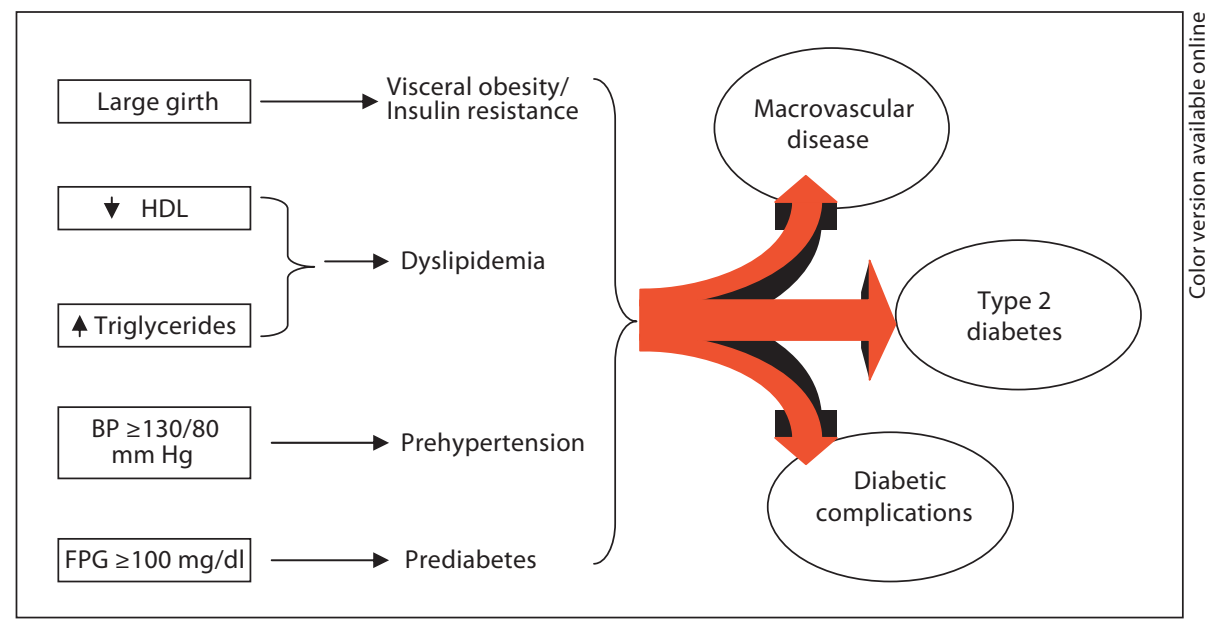

factors for type 2 diabetes, and persons with these conditions progress to type 2 diabetes at variable rates.

Epidemiological studies, including the Paris Prospective Study [2], have shown that prediabetes confers an increased risk of cardiovascular disease (CVD). Patients who progress to type 2 diabetes manifest an additional risk for atherosclerotic disorders, resulting in an increased burden of CVD, stroke and peripheral vascular diseases, compared with nondiabetic subjects [3].

The metabolic syndrome [4] appears to be the link between prediabetes and macrovascular disease. Most patients with prediabetes have features of the insulin resistance (metabolic) syndrome, including upper-body obesity, hypertriglyceridemia, decreased HDL cholesterol levels and hypertension, among others. Components of the metabolic syndrome can be identified in prediabetic subjects several years before the diagnosis of type 2 diabetes.

\section{Definition}

Although several overlapping definitions exist for the metabolic syndrome, the definition proposed by the $\mathrm{Na}-$ tional Cholesterol Education Program (NCEP) that focuses on abdominal obesity, low HDL cholesterol $(<40$ $\mathrm{mg} / \mathrm{dl}$ in men and $<50 \mathrm{mg} / \mathrm{dl}$ in women), triglycerides $(>150 \mathrm{mg} / \mathrm{dl})$, blood pressure $(>130 / 80 \mathrm{~mm} \mathrm{Hg}$ ) and fasting plasma glucose (>100 mg/dl) has the merit of simplicity and specific numerical cutoff points (table 1).

Other definitions have attempted to introduce ethnic, racial and geographical adjustments for abdominal obesity (waist circumference), or incorporate additional risk markers (e.g., microalbuminuria, uric acid, etc.). Epidemiological studies, based on the NCEP criteria for the
Table 1. NCEP criteria for the metabolic syndrome

$\begin{array}{ll}\begin{array}{l}\text { Abdominal obesity } \\ \text { (waist circumference) }\end{array} & \\ \quad \text { Men } & >102 \mathrm{~cm}(>40 \mathrm{in}) \\ \quad \text { Women } & >88 \mathrm{~cm}(>35 \mathrm{in}) \\ \text { Triglycerides } & \geq 150 \mathrm{mg} / \mathrm{dl} \\ \text { HDL cholesterol } & \\ \quad \text { Men } & <40 \mathrm{mg} / \mathrm{dl} \\ \quad \text { Women } & <50 \mathrm{mg} / \mathrm{dl} \\ \text { Blood pressure } & \geq 130 / 85 \mathrm{~mm} \mathrm{Hg} \\ \text { Fasting glucose } & \geq 100 \mathrm{mg} / \mathrm{dl}\end{array}$

The diagnosis is established when $>3$ of these risk factors are present. Adapted from the Expert Panel on Detection, Evaluation, and Treatment of High Blood Cholesterol in Adults [4].

metabolic syndrome, have reported an alarming prevalence of the syndrome [5]. Such studies also have observed a significant concordance between components of the metabolic syndrome and the occurrence of inflammatory markers, diabetes and CVD [6]. Moreover, progression from individual components of the metabolic syndrome to specific downstream disorders (fig. 1) can be deduced from longitudinal observation studies (e.g., dyslipidemia and hypertension lead to CVD, obesity and impaired fasting glucose lead to type 2 diabetes).

The prevalence of type 2 diabetes has reached epidemic proportions. Diabetes is now the leading cause of blindness, end-stage renal failure and nontraumatic limb amputations. Furthermore, diabetes is the leading underlying cause of coronary heart disease, stroke and peripheral vascular disease [7]. The association of hyperglyce- 
mia with CVD endpoints has been demonstrated among diabetic patients $[3,8,9]$ as well as the general populace [10], but recent intervention studies have failed to show a CVD benefit of aggressive glycemic control among patients with long-standing type 2 diabetes and preexisting CVD [11-13]. These 'negative' trials [11-13] provide a strong rationale for focusing on primary prevention and early intervention to reduce cardiometabolic risks.

\section{Additive Metabolic Risks from Tobacco Use}

Cohort studies have found that cigarette smoking is associated with an additional increase in the risk of cardiovascular death among people with diabetes, up to fourfold, depending on the amount smoked [14]. Notably, $\mathrm{HbAlc}$ and lipoprotein levels have been reported to be higher in diabetic patients with a current history of cigarette smoking compared with nonsmokers $[15,16]$. Cigarette smoking also is a risk factor for the metabolic syndrome [17]. The mechanism(s) for the association between smoking and increased risks for the metabolic syndrome and diabetic complications include the induction of insulin resistance, increased hepatic lipase activity and dyslipidemia [15-17]. Other contributory factors include the chronic elevation of stress hormones, endothelial dysfunction and the vasoconstrictive effect of nicotine. It is reasonable to expect that smoking cessation would lessen the cardiometabolic risk through the amelioration of these noxious effects of nicotine. However, rigorous studies testing the latter notion are yet to be reported.

\section{Rationale for Primary Prevention}

Without effective intervention, the components of the metabolic syndrome increase the risks for CVD and type 2 diabetes (fig. 1). Once established, type 2 diabetes is difficult to treat. Glycemic control is often suboptimal, and there is a direct relationship between poor diabetes control and the development of the long-term complications that drive health care costs. Although aggressive glycemic control has been advocated as the best insurance against the development of costly complications, the achievement of sustained glycemic control to the level necessary for the prevention of complications often proves elusive.

The rationale for the primary prevention of diabetes and its complications rests on four premises: (a) the prediabetic milieu of the metabolic syndrome increases the risk for fatal CVD; (b) the risk factors for the metabolic syndrome and diabetes (table 2) overlap considerably; (c) there are consensus guidelines for the recognition of the
Table 2. Risk factors for prediabetes and type 2 diabetes

Family history of type 2 diabetes

Overweight/obesity

Physical inactivity

Ethnicity

Gestational diabetes

Delivery of baby weighing $\geq 9 \mathrm{lb}(4.1 \mathrm{~kg})$

Hypertension

Dyslipidemia

metabolic syndrome; (d) the progression from individual components of the metabolic syndrome to their cognate downstream disorders can be prevented or delayed by established methods.

Lifestyle interventions have been shown to exert beneficial effects on each of the individual components of the metabolic syndrome as defined by the NCEP. The specific elements of lifestyle change utilized in randomized controlled studies often include dietary modification and physical activity.

\section{Lifestyle Change and Risk of Diabetes}

Three landmark studies have demonstrated the efficacy of lifestyle intervention in preventing the development of type 2 diabetes in high-risk individuals [18-20]. All studies targeted persons with prediabetes (IGT). The lifestyle interventions applied in these studies generally involved the induction of modest weight loss (approx. 5 to $<10 \%)$ through dietary modification and/or increased physical activity. The dietary modifications involved a reduction in caloric consumption, a selective reduction in saturated fat calories, and an increase in complex carbohydrates. The physical activity component involved the accrual of an additional 150-240 min per week of voluntary, moderate-intensity (approx. 55\% $\mathrm{VO}_{2}$ max) physical activity above routine levels [18-20]. The primary outcome measure was the rate of progression from IGT to type 2 diabetes over a defined period (approx. 3-6 years) of observation in the intervention arm versus a comparison group.

\section{Chinese and Finnish Studies}

Investigators in the Da Qing Study [18] enrolled 577 Chinese adults (mean age: 45 years; mean body mass index, BMI: 26) who met the WHO criteria for IGT. Subjects were randomized by clinic to a control group or to 
1 of 3 active treatment groups: diet only, exercise only or diet plus exercise. The dietary policy had a target BMI of $<23$; the exercise goal was an increase in physical activity of $210 \mathrm{~min}$ per week ( $30 \mathrm{~min}$ daily). The study subjects were seen approximately every 2 weeks during the first 3 months, and quarterly thereafter. The cumulative incidence of diabetes at 6 years was $67.7 \%$ in the control group compared with $43.8 \%$ in the diet group, $41.1 \%$ in the exercise group, and $46.0 \%$ in the diet-plus-exercise group. Cox's proportional hazards analysis, adjusted for differences in baseline BMI and fasting glucose, showed that the diet, exercise and diet-plus-exercise interventions resulted in 31,46 and $42 \%$ reductions in the risk of developing diabetes, respectively, compared with the control group. Thus, diet and/or exercise interventions significantly reduced the incidence of diabetes over a 6-year period among persons with IGT. Curiously, the Da Qing Study failed to show an additive effect of diet plus exercise on the primary endpoint.

In the Finnish Diabetes Prevention Study (FDPS) [19], 522 middle-aged subjects ( 172 men and 350 women; mean age: 55 years; mean BMI: 31) were randomly assigned to either an intervention or control group. All participants had IGT at enrollment. Each subject in the intervention group received individualized counseling aimed at inducing approximately $5 \%$ weight loss through the reduction of total and saturated fat intake and increased intake of fiber. In addition, the participants were instructed to increase their physical activity by approximately $210 \mathrm{~min}$ per week. The mean weight loss by the end of the second year was approximately $3.5 \mathrm{~kg}$ in the intervention group and approximately $0.8 \mathrm{~kg}$ in the control group. The cumulative incidence of diabetes after 4 years was $11 \%$ in the intervention group and $23 \%$ in the control group, a significant $58 \%$ reduction in diabetes incidence.

\section{Diabetes Prevention Program}

The lifestyle intervention arm of the Diabetes Prevention Program (DPP) enrolled 1,079 subjects with IGT (out of the 3,234 participants enrolled in the study) drawn from all ethnic and racial groups in the US population [20]. The two major goals of the DPP lifestyle intervention were a minimum of $7 \%$ weight loss/weight maintenance and a minimum of 150 min of physical activity similar in intensity to brisk walking. The goals for the participants assigned to the intensive lifestyle intervention were to achieve and maintain a weight reduction of at least $7 \%$ of the initial body weight through modest caloric restriction (500-700 fewer calories per day) and to engage in physical activity of moderate intensity, such as brisk walking, for at least $150 \mathrm{~min}$ per week. After an average follow-up period of 2.8 years, the participants randomized to lifestyle intervention showed a $58 \%$ reduction in the incidence of diabetes, as compared with placebo [20]. This beneficial effect of lifestyle intervention was seen in all age, gender, racial and ethnic subgroups of the DPP participants. Furthermore, reversion to normal glucose tolerance occurred in approximately $30 \%$ of the subjects in the lifestyle intervention arm, as compared with approximately $18 \%$ in the control arm. Thus, caloric restriction and increased physical activity not only prevented progression from IGT to diabetes, but were also effective in restoring normal glucose tolerance in a substantial proportion of subjects with initial IGT [20].

\section{Effect of Lifestyle Change on Components of the}

Metabolic Syndrome

The DPP investigators [21] assessed the effects of lifestyle intervention, metformin and placebo on CVD risk factors and markers of the metabolic syndrome among subjects with IGT. Compared with the placebo and metformin arms, subjects assigned to lifestyle intervention showed decreased blood pressure, increased HDL cholesterol levels and lower triglyceride levels during approximately 3 years of follow-up. Intensive lifestyle modification was also associated with a reduction in the more atherogenic small, dense LDL particles [21]. Consonant with the foregoing findings, there was a reduced need for antihypertensive and lipid-lowering medications among subjects assigned to the intensive lifestyle arm.

Besides reducing the need for antihypertensive medications, lifestyle intervention had a profound effect on the occurrence of new cases of hypertension in the DPP. The prevalence of hypertension at baseline was approximately $30 \%$ in the 3 comparison groups. After 3 years of follow-up, the prevalence increased to approximately $40 \%$ in the placebo and metformin arms but remained at approximately $30 \%$ in the intensive lifestyle group, which represents a risk reduction of $33 \%$ in the lifestyle group, compared with placebo or metformin treatment [21,22]. This finding is in agreement with the well-known favorable effect of exercise and dietary modification on the regulation of blood pressure.

\section{'Epigenetic' Effects of Lifestyle Intervention}

Emerging data from landmark clinical trials such as the DPP and FDPS indicate significant gene-lifestyle interactions in predicting progression from prediabetes to type 2 diabetes [23-25]. A significant interaction between the G308A and A308A alleles of the tumor necrosis fac- 
Table 3. Gene-by-lifestyle interactions in diabetes prevention studies

\begin{tabular}{llll}
\hline Gene & Association & $\begin{array}{l}\text { Risk } \\
\text { reduction }\end{array}$ & Source \\
\hline TCF7L2 & type 2 diabetes & $66 \%$ & DPP [24] \\
ENPP1 & type 2 diabetes & $55 \%$ & DPP [25] \\
TNF- $\alpha$ (-308A allele vs. G308G genotype) & type 2 diabetes & - & FDPS [23] \\
PPARG (Pro12Ala genotype) & obesity & $20 \%$ & DPP [28, 29] \\
\hline
\end{tabular}

TNF- $\alpha$ polymorphism predicted diabetes in the lifestyle arm only. $P P A R G=$ Peroxisome proliferator-activated receptor- $\gamma$.

tor- $\alpha(T N F-\alpha)$ gene and the development of diabetes was observed among the subjects assigned to lifestyle intervention in the FDPS [23]. Furthermore, a microsatellite within intron 3 of the transcription factor 7-like 2 (TCF7L2) gene, located on chromosome 10q, has been strongly associated with type 2 diabetes [26]. TCF7L2 is thought to act through the modulation of proglucagon gene expression, incretin processing and insulin secretion in enteroendocrine cells [26]. The two most strongly associated TCF7L2 variants are rs 12255372 and rs7903146.

In the DPP, 3,548 study subjects with prediabetes at baseline were genotyped for TCF7L2 variants and Cox's regression analysis was performed using genotype, intervention and their interactions as predictors [24]. The DPP investigators also assessed the effect of genotype on measures of insulin secretion and insulin sensitivity at baseline and at 1 year, and on progression from prediabetes to type 2 diabetes. Over a period of 3 years, participants with the risk-conferring TT genotype at rs7903146 were more likely to have progressed from prediabetes to diabetes than were CC homozygotes [24]. Interestingly, the diabetogenic effect of the TT genotype was strongest in the placebo group and weakest in the lifestyle intervention group (hazard ratio: 1.81 vs. $1.15 ; \mathrm{p}=0.0004$ ). This translates to a $66 \%$ risk reduction in the lifestyle group. Furthermore, the TT genotype was associated with decreased insulin secretion at baseline. Essentially similar results were obtained for the rs12255372 gene variant, and the effects were consistent across race/ethnicity [24].

The DPP investigators have carried out a similar analysis for the ectoenzyme nucleotide pyrophosphatase phosphodiesterase 1 (ENPP1) gene [25]. ENPP1 inhibits insulin signaling, and the Q allele in the K121Q polymorphism is associated with type 2 diabetes [27]. In the DPP, carriers of the Q allele had a $38 \%$ greater risk of progres- sion from prediabetes to diabetes compared to KK homozygotes, and lifestyle intervention significantly decreased that effect (table 3) [25]. Also, a polymorphism of the peroxisome proliferator-activated receptor- $\gamma$ gene involving proline-for-alanine substitution at position 12 (Pro12Ala polymorphism) was associated with obesity and future diabetes risk in the DPP study $[28,29]$. In the placebo group, body fat decreased in Ala12 allele carriers, but was unchanged in Pro12 homozygotes. Following lifestyle intervention, body fat decreased across the genotypes, but the reduction was greater in Ala12 carriers [28].

\section{Translation to the Community}

The keys to the translation of lifestyle change to the community consist of evidence-based change in practices of physicians and primary care providers, the education and mobilization of the lay public for behavior change, and the involvement of civic and health care leadership.

The information and knowledge base of the health care community can be steered toward emphasizing lifestyle intervention through a number of established approaches. First, curriculum development in primary and high schools should incorporate information on the prevention of diabetes and cardiometabolic risk within a wider context of wellness and health promotion. Second, students in schools of medicine, nursing, pharmacy and allied medical fields must receive adequate exposure to formal instruction in the design and key findings of these landmark prevention studies. Third, understanding the principles and methods of lifestyle intervention in the primary prevention of chronic metabolic disorders should become a priority in the core curriculum of residency training programs. Finally, the knowledge base of practicing physicians in all disciplines (including internists, family physicians, endocrinologists, cardiologists, ne- 
phrologists, general and specialist surgeons), nurse practitioners and other primary care providers must be continually updated, with particular emphasis on the efficacy of lifestyle change. To reach an even wider segment of society, however, requires additional coordinated efforts at the local, regional, state, national and international levels [30, 31].

\section{Strategies for Lifestyle Change in the Community}

The lifestyle intervention in the DPP utilized 5 key approaches, many of which could be adapted for implementation in the community setting.

Selection of Persons at Risk. The DPP utilized the risk factor approach (table 2) to screen persons for enrollment. This approach proved to be legitimate because the participants randomized to placebo did in fact develop diabetes at an alarming rate (approx. 12\% per year) [20]. It must be noted, though, that a family history of diabetes was not included in the NCEP criteria for recognition of the metabolic syndrome, and the BMI (rather than waist circumference) was used as a marker of obesity in the DPP. The differences between the NCEP criteria and the DPP risk markers may actually cancel out since the inclusion of visceral obesity in the former enriches the risk pool for diabetes and CVD, while the inclusion of familial risk is likely to do the same for the DPP criteria. Targeting persons with a positive family history of type 2 diabetes or CVD who have a high BMI $(>24)$ or a large girth $(>102 \mathrm{~cm}$ in men, $>88 \mathrm{~cm}$ in women), dyslipidemia and a fasting plasma glucose of $>100 \mathrm{mg} / \mathrm{dl}$ [32] should produce a high yield of eligible individuals for lifestyle intervention in the community. The BMI cutoff should be lowered to $>22$ for Asians [33]. Similarly, lower thresholds for waist circumference in Asian men and women have been proposed by the International Diabetes Federation.

Increasing Physical Activity. The landmark studies [18-20] have demonstrated the efficacy and safety of moderate-intensity physical activity (150-210 min per week of walking or other aerobic activity) on the reduction of obesity, prevention of diabetes and amelioration of components of the metabolic syndrome. In the DPP, screening with submaximal cardiac stress testing was performed before the initiation of the exercise intervention program. The physical activity intervention was not associated with any untoward cardiovascular events or injuries. Therefore, routine cardiac stress testing prior to the initiation of moderate physical activity is unnecessary in otherwise healthy subjects. Given that the intensity of exercise in the DPP (equivalent to brisk walking) was not much higher than usual activities in healthy sub- jects, selective cardiac screening for persons with a history of angina or CVD (rather than universal screening) would seem prudent. Nonetheless, persons who have been chronically sedentary should initiate physical activity gradually (perhaps for 10 min daily) and increase slowly to a level of $30 \mathrm{~min}$ daily. All persons should include a warm-up period at the beginning of the exercise session. Because of the high prevalence of the metabolic syndrome and the low rate of physical activity [34], novel strategies will be required to raise national levels of physical activity, particularly among high-risk populations.

Individual Case Managers or 'Lifestyle Coaches'. Frequent contacts (weekly to bimonthly) between participants and individual lifestyle coaches were necessary to prove the concept of primary prevention of diabetes and associated metabolic disorders [35]. For translation to the community at large, a less intense interaction model involving groups of at-risk persons (rather than one-on-one sessions) would be more practical, given the constraints of cost and personnel. At these group meetings, the lifestyle coach or group leader sets targets and uses nondirective approaches to the augmentation of minutes spent in daily physical activity. Opportunities for increasing physical activity at home, in the work place and in the community are identified. The value of making small, steady changes toward an eventual accrual of at least 30 min of daily physical activity is stressed.

Dietary Modification. The participants in the landmark diabetes prevention studies $[18-20,35]$ were asked to reduce their intake of fat calories to $<30 \%$ and total calories by $500-700 \mathrm{kcal}$ per day. This element of lifestyle change was accomplished initially through weekly oneon-one sessions with a dietitian for 24 weeks, followed by monthly sessions. The FDPS utilized a less intensive schedule (7 sessions in year 1, then every 3 months) and achieved a similar reduction in diabetes risk as did the DPP. Thus, following an initial dietary counseling session, maintenance visits at approximately 3 -month intervals could well suffice as an effective intervention in the community setting. However, at such dietary counseling sessions, emphasis needs to be placed on specific dietary modifications that have proven to be effective. Evidence of such a focused dietary counseling was seen in a study involving 120 obese women followed for 2 years, in which subjects who received education about exercise and how to lose weight through a Mediterranean-style diet had greater weight loss than those who received general information about healthy food and exercise (14 vs. $3 \mathrm{~kg}$; p < 0.001) [36]. 
Self-Monitoring. The self-monitoring of food intake and of the accrual of physical activity minutes is a valuable adjunct to effective lifestyle change [37]. The objective monitoring of weight by a community interventionist also could be a source of motivation. For these reasons, any program of lifestyle change in the community must incorporate tools for behavioral self-monitoring and make provisions for on-site objective monitoring of weight, waist circumference and other relevant metabolic endpoints. Clearly, the hospital- or clinic-based disease management system would be most unsuitable for the implementation of lifestyle change among the vast majority of asymptomatic persons in the community. For such persons, the creation of novel primary prevention or wellness centers in the community would provide an efficient vehicle for the translation of these strategies.

\section{Summary}

Dietary modification, regular physical activity, smoking cessation and other lifestyle changes have been shown to exert favorable effects on glycemia, blood pressure, body weight, fat distribution, and lipid and lipoprotein profiles, among other metabolic and psychological benefits. Thus, all the components of the metabolic syndrome are sensitive to lifestyle intervention. The effects of lifestyle intervention have been demonstrated to result in the primary prevention of type 2 diabetes, hypertension and dyslipidemia in prediabetic subjects. In the DPP, the benefits of lifestyle change were observed universally across all age and BMI groups, whereas the effect of metformin was restricted to young obese persons [20,38]. Furthermore, emerging data suggest that lifestyle intervention might exert 'epigenetic' effects that translate to the prevention or delay of progression from prediabetes to diabetes [23-29]. These fascinating observations provide novel mechanisms whereby behavioral interventions can alter the expression of genetic diseases.

Among patients with isolated diabetes, hypertension, dyslipidemia or the metabolic syndrome, lifestyle change is an important adjunct to medications. However, direct evidence is still lacking with regard to the beneficial effects of lifestyle interventions (except for smoking cessation) on mortality and cardiovascular events. The ongoing National Institutes of Health-sponsored Look AHEAD study might provide answers in the future [39].

For the tens of millions of people in the USA and the hundreds of millions worldwide who have the metabolic syndrome, lifestyle modification is the most appealing
Table 4. Empowering lifestyle change in the community

Incorporation of wellness and prevention in school curriculum Coordination of efforts at multiple levels within the society

Enactment of policy changes that stimulate broad societal participation

Access to safe walking trails, and well-kept and well-lit public parks

Creation of accessible and affordable neighborhood fitness centers

Increased nutritional education and changes in food offerings and advertising

Legislation that rewards healthful behavior and discourages harmful behavior

Creation of community primary prevention or wellness centers

and most compelling initial approach because of its nontoxicity and superb efficacy, compared with medications. Furthermore, the predicted massive surge in future diabetes rates in developing countries makes timely nonpharmacological prevention all the more compelling [40]. The implementation of either primary or adjunctive lifestyle intervention for the prevention or management of cardiometabolic disorders in the community requires coordinated efforts at multiple levels within the health care establishment and society. At the highest level of civic organization, environmental and policy changes that stimulate broad societal participation in physical activity and the adoption of healthful diets need to be enacted. As a minimum, these policies need to ensure access to safe walking trails, well-kept public parks, accessible and affordable neighborhood fitness centers, changes in food offerings and advertising, and novel approaches to nutritional counseling. Appropriate legislation [41] that promotes and rewards healthful behavior and discourages harmful behavior may also be considered (table 4). Finally, it must be noted that the clinical studies [18-20] used a rather intensive lifestyle modification to achieve beneficial metabolic endpoints. For practical purposes, the effectiveness of less intensive interventions needs to be demonstrated in the general population. There are some ongoing translational studies that might provide such data in the future [42].

\section{Acknowledgments}

The authors acknowledge support from the National Institutes of Health (grants R01 DK067269 and M01 RR00211) and the American Diabetes Association. 


\section{References}

1 American Diabetes Association: Diagnosis and classification of diabetes mellitus. Diabetes Care 2009;32(suppl 1):S62-S67.

2 Eschwege E, Richard JL, Thibult N, Ducimetière P, Warnet JM, Claude JR, Rosselin GE: Coronary heart disease mortality in relation with diabetes, blood glucose and plasma insulin levels: the Paris Prospective Study, ten years later. Horm Metab Res 1985; 15(suppl):41-46.

-3 Stratton IM, Adler AI, Neil HA, Matthews DR, Manley SE, Cull CA, Hadden D, Turner RC, Holman RR: Association of glycaemia with macrovascular and microvascular complications of type 2 diabetes (UKPDS 35): prospective observational study. BMJ 2000; 321:405-412.

$\checkmark 4$ Expert Panel on Detection, Evaluation, and Treatment of High Blood Cholesterol in Adults: Executive summary of the Third Report of the National Cholesterol Education Program (NCEP) Expert Panel on Detection, Evaluation, and Treatment of High Blood Cholesterol in Adults (Adult Treatment Panel III). JAMA 2001;285:24862497.

5 Ford ES, Giles WH, Dietz WH: Prevalence of the metabolic syndrome among US adults: findings from the Third National Health and Nutrition Examination Survey. JAMA 2002; 287:356-359.

6 Ridker PM, Buring JE, Cook NR, Rifai N: Creactive protein, the metabolic syndrome, and risk of incident cardiovascular events: an 8-year follow-up of 14,719 initially healthy American women. Circulation 2003;107: 391-397.

7 Saydah SH, Fradkin J, Cowie CC: Poor control of risk factors for vascular disease among adults with previously diagnosed diabetes. JAMA 2004;291:335-342.

-8 DCCT/EDIC Research Group: Intensive diabetes treatment and cardiovascular disease in type 1 diabetes in the DCCT/EDIC. $\mathrm{N}$ Engl J Med 2005;353:2643-2653.

9 Dagogo-Jack S: Primary prevention of cardiovascular disease in diabetic patients. Cardiol Q 2006; 12:20-25.

$\checkmark 10$ Khaw KT, Wareham N, Bingham S, Luben R, Welch A, Day N: Association of hemoglobin A1c with cardiovascular disease and mortality in adults: the European prospective investigation into cancer in Norfolk. Ann Intern Med 2004;141:413-420.

-11 Action to Control Cardiovascular Risk in Diabetes Study Group: Effects of intensive glucose lowering in type 2 diabetes. $\mathrm{N}$ Engl J Med 2008;358:2545-2559.

-12 ADVANCE Collaborative Group: Intensive blood glucose control and vascular outcomes in patients with type 2 diabetes. $\mathrm{N}$ Engl J Med 2008;358:2560-2572-2559.
13 Duckworth W, Abraira C, Moritz T, Reda D, Emanuele N, Reaven PD, Zieve FJ, Marks J, Davis SN, Hayward R, Warren SR, Goldman S, McCarren M, Vitek ME, Henderson WG, Huang GD, VADT Investigators: Glucose control and vascular complications in veterans with type 2 diabetes. N Engl J Med 2009; 360:129-139.

14 Miyatake N, Wada J, Kawasaki Y, Nishii K, Makino H, Numata T: Relationship between metabolic syndrome and cigarette smoking in the Japanese population. Intern Med 2006; 45:1039-1043.

15 Facchini FS, Hollenbeck CB, Jeppesen J, Chen YD, Reaven GM: Insulin resistance and cigarette smoking. Lancet 1992;339: 1128-1130.

16 Heitzer T, Ylä-Herttuala S, Luoma J, Kurz S, Münzel T, Just H, Olschewski M, Drexler H: Cigarette smoking potentiates endothelial dysfunction of forearm resistance vessels in patients with hypercholesterolemia: role of oxidized LDL. Circulation 1996;9:13461353.

17 Kong C, Nimmo L, Elatrozy T, Anyaoku V, Hughes C, Robinson S, Richmond W, Elkeles RS: Smoking is associated with increased hepatic lipase activity, insulin resistance, dyslipidaemia and early atherosclerosis in type 2 diabetes. Atherosclerosis 2001;156:373378.

18 Pan XR, Li GW, Hu YH, Wang JX, Yang WY, An ZX, Hu ZX, Lin J, Xiao JZ, Cao HB, Liu PA, Jiang XG, Jiang YY, Wang JP, Zheng $H$, Zhang H, Bennett PH, Howard BV: Effects of diet and exercise in preventing NIDDM in people with impaired glucose tolerance. The Da Qing IGT and Diabetes Study. Diabetes Care 1997;20:537-544.

19 Tuomilehto J, Lindström J, Eriksson JG, Valle TT, Hämäläinen H, Ilanne-Parikka $\mathrm{P}$, Keinänen-Kiukaanniemi S, Laakso $\mathrm{M}$, Louheranta A, Rastas M, Salminen V, Uusitupa M, Finnish Diabetes Prevention Study Group: Prevention of type 2 diabetes mellitus by changes in lifestyle among subjects with impaired glucose tolerance. N Engl J Med 2001;344:1343-1350.

20 Diabetes Prevention Program Research Group: Reduction in the incidence of type 2 diabetes with lifestyle intervention or metformin. N Engl J Med 2002;346:393-403.

21 Diabetes Prevention Program Research Group: Impact of intensive lifestyle and metformin therapy on cardiovascular disease risk factors in the Diabetes Prevention Program. Diabetes Care 2005;28:888-894.

22 Dagogo-Jack S: Primary prevention of cardiovascular disease in pre-diabetes: the glass is half-full and half-empty (editorial). Diabetes Care 2005;28:971-972.
23 Kubaszek A, Pihlajamäki J, Komarovski V, Lindi V, Lindström J, Eriksson J, Valle TT, Hämäläinen H, Ilanne-Parikka P, KeinänenKiukaanniemi S, Tuomilehto J, Uusitupa M, Laakso M, Finnish Diabetes Prevention Study Group: Promoter polymorphisms of the TNF-alpha (G-308A) and IL-6 (C-174G) genes predict the conversion from impaired glucose tolerance to type 2 diabetes: the Finnish Diabetes Prevention Study. Diabetes 2003;52:1872-1876

24 Florez JC, Jablonski KA, Bayley N, Pollin TI, de Bakker PI, Shuldiner AR, Knowler WC, Nathan DM, Altshuler D, Diabetes Prevention Program Research Group: TCF7L2 polymorphisms and progression to diabetes in the Diabetes Prevention Program. N Engl J Med 2006;355:241-250.

25 Moore AF, Jablonski KA, Mason CC, McAteer JB, Arakaki RF, Goldstein BJ, Kahn SE, Kitabchi AE, Hanson RL, Knowler WC, Florez JC, Diabetes Prevention Program Research Group: The association of ENPP1 K121Q with diabetes incidence is abolished by lifestyle modification in the diabetes prevention program. J Clin Endocrinol Metab 2009;94:449-455.

-26 Grant SF, Thorleifsson G, Reynisdóttir I, Benediktsson R, Manolescu A, Sainz J, Helgason A, Stefansson H, Emilsson V, Helgadóttir A, Styrkarsdóttir U, Magnusson KP, Walters GB, Palsdóttir E, Jonsdóttir T, Guðmundsdóttir T, Gylfason A, Sæmundsdóttir J, Wilensky RL, Reilly MP, Rader DJ, Bagger Y, Christiansen C, Guðnason V, Sigurðsson G, Thorsteinsdóttir U, Gulcher JR, Kong A, Stefánsson K: Variant of transcription factor 7-like 2 (TCF7L2) gene confers risk of type 2 diabetes. Nat Genet 2006;38:320-323.

$\checkmark 27$ Abate N, Chandalia M, Satija P, Adams-Huet B, Grundy SM, Sandeep S, Radha V, Deepa R, Mohan V: ENPP1/PC-1 K121Q polymorphism and genetic susceptibility to type 2 diabetes. Diabetes 2005;54:1207-1213

28 Diabetes Prevention Program Research Group: The Pro12Ala variant at the peroxisome proliferator-activated receptor gamma gene and change in obesity-related traits in the Diabetes Prevention Program. Diabetologia 2007;50:2451-2460.

29 Florez JC, Jablonski KA, Sun MW, Bayley N, Kahn SE, Shamoon H, Hamman RF, Knowler WC, Nathan DM, Altshuler D, Diabetes Prevention Program Research Group: Effects of the type 2 diabetes-associated PPARG P12A polymorphism on progression to diabetes and response to troglitazone. J Clin Endocrinol Metab 2007;92:1502-1509.

30 Kriska A: Striving for a more active community: lessons from the Diabetes Prevention Program and beyond. Am J Prev Med 2002; 22:6-7. 
-31 Zimmet P, Shaw J, Alberti KGMM: Preventing type 2 diabetes and the dysmetabolic syndrome in the real world: a realistic view. Diabet Med 2003;20:693-702.

-32 Dagogo-Jack S, Askari H, Tykodi G: Glucoregulatory physiology in subjects with lownormal, high-normal, or impaired fasting glucose. J Clin Endocrinol Metab 2009;94: 2031-2036.

>33 Pan WH, Flegal KM, Chang HY, Yeh WT, Yeh CJ, Lee WC: Body mass index and obesity-related metabolic disorders in Taiwanese and US whites and blacks: implications for definitions of overweight and obesity for Asians. Am J Clin Nutr 2004;79:31-39.

-34 Kimm SY, Glynn NW, Kriska AM, Barton BA, Kronsberg SS, Daniels SR, Crawford PB, Sabry ZI, Liu K: Decline in physical activity in black and white girls during adolescence. N Engl J Med 2002;347:709-715.
35 Diabetes Prevention Program Research Group: The Diabetes Prevention Program (DPP): description of lifestyle intervention. Diabetes Care 2002;25:2165-2171.

36 Esposito K, Pontillo A, di Palo C, Giugliano G, Masella M, Marfella R, Giugliano D: Effect of weight loss and lifestyle changes on vascular inflammatory markers in obese women: a randomized trial. JAMA 2003;289: 1799-1804.

37 Butryn ML, Phelan S, Hill JO, Wing RR: Consistent self-monitoring of weight: a key component of successful weight loss maintenance. Obesity (Silver Spring) 2007;15:30913096.
38 Diabetes Prevention Program Research Group: Effects of withdrawal from metformin on the development of diabetes in the Diabetes Prevention Program. Diabetes Care 2003;26:977-980.

39 Look AHEAD Research Group: Reduction in weight and cardiovascular disease risk factors in individuals with type 2 diabetes: one-year results of the Look AHEAD trial. Diabetes Care 2007;30:1374-1383.

40 Dagogo-Jack S: Primary prevention of type 2 diabetes in developing countries. J Natl Med Assoc 2006;98:415-419.

41 Collins SM: Legislative perspectives on diabetes in America. Endocr Pract 2002;8(suppl 1):17-18.

42 Ackermann RT, Finch EA, Brizendine E, Zhou H, Marrero DG: Translating the Diabetes Prevention Program into the community: the DEPLOY Pilot Study. Am J Prev Med 2008;35:357-363. 